
dezembro 2002.

\title{
Fibra da casca do coco verde como substrato agrícola
}

\author{
Osmar Alves Carrijo ${ }^{1}$; Ronaldo Setti de Liz $^{2}$; Nozomu Makishima ${ }^{1}$ \\ ${ }^{1}$ Embrapa Hortaliças, C. Postal 218, 70.359-970 Brasília-DF; E-mail: carrijo@cnph.embrapa.br; \\ ${ }^{2}$ Aluno de Agronomia. Faculdade da Terra, Brasília-DF. Bolsista da Embrapa Hortaliças
}

\section{RESUMO}

A produção comercial de mudas e o cultivo sem solo de hortaliças estão se tornando práticas comuns entre os olericultores. Vários materiais orgânicos como as turfas, resíduos de madeira, casca de pinus e de arroz parcialmente carbonizada ou não, ou materiais inorgânicos como areia, rochas vulcânicas, perlita, lã de rocha e a espuma fenólica já são utilizados como substratos, isoladamente ou em composição. A casca de coco verde que em muitas regiões causa transtorno ao serviço de limpeza pública pelo volume e pela dificuldade de decomposição produz uma fibra que pode ser utilizada como substrato. Para a produção da fibra, a casca de coco verde é picada, desfibrada, triturada, lavada e secada. Para o uso como substrato na produção de mudas, a fibra deve passar por um processo de compostagem. Este processo não é necessário para o uso como substrato em cultivo sem solo, mas no entanto, o substrato necessitará ser enriquecido com nutrientes em pré-plantio ou em fertirrigação. $\mathrm{O}$ uso do substrato da fibra de coco verde na produção de tomate em casa de vegetação, alcançou, em termos absolutos, $13,2 \mathrm{~kg} \mathrm{~m}^{-2}$ de frutos comerciais (média de 3 anos) cerca de 7,3\% mais que o segundo melhor substrato, o pó de serra com $12,3 \mathrm{~kg} \mathrm{~m}^{-2}$.

Palavras-chave: cultivo sem solo, fertirrigação.

\section{ABSTRACT}

Fiber of green coconut shell as an agricultural substrate

Commercial seedling production and vegetable soilless cultivation are becoming common techniques among vegetable growers around the world. Several organic materials as peat, wood residue, pine bark, rice husk, or inorganic materials as sand, volcanic rocks, perlite, rockwool have been used alone or in mixture with others. Green coconut shells are becoming a major problem for the litter public service in many cities in Brazil, due to the large amount of material and its slow decomposition process. Recently, fibers extracted from coconut shells are being used as substrate. The coconut shells for the substrate production need to be cut, disintegrated in fibers, washed, dried and ground. For seedling production the manufactured coconut fiber substrate needs to be composted. The composting process is not necessary for flowers and vegetable soilless cultivation, but nutrients should be added in pre-plant or by fertigation. Tomatoes cultivated on coconut fiber substrate produced $13,2 \mathrm{~kg} \mathrm{~m}^{-2}$ of marketable fruits (three years average). This production was about $7,3 \%$ more than the production on sawdust $\left(12,3 \mathrm{~kg} \mathrm{~m}^{-2}\right)$.

Keywords: soilless cultivation, fertigation.

\section{(Recebido para publicação em 08 de novembro de 2001 e aceito em12 de setembro de 2002)}

$\mathrm{O}$ consumo da água de coco verde no Brasil é crescente e significativo. A grande demanda é suprida, principalmente, pela extração da água do fruto in natura. No ano de 2000 já haviam no país cerca de 80 indústrias de pequeno e três de grande porte, envasando a água de coco que concorre diretamente com o mercado de refrigerantes. Segundo a Associação Brasileira das Indústrias da Alimentação (ABIA) são consumidos no país 10 bilhões de litros/ano de refrigerantes. $\mathrm{O}$ consumo de água de coco representa $1,4 \%$ deste mercado ou seja 140 milhões de litros. Este volume é considerado ainda muito pequeno pela Associação Brasileira dos Produtores de Coco (ASBRACOCO) que pretende atingir 5\% deste mercado ou seja, 500 milhões de litros/ano (Brasil, 1998). A casca de coco verde, subproduto do uso e da industrialização da água de coco, é depositada em lixões e às margens de estradas. É um material de difícil decomposição levando mais de 8 anos para se decompor. Portanto, a utilização da casca do coco verde processada, além da importância econômica e social, é também importante do ponto de vista ambiental. Segundo Rosa et al. (2001) $80 \%$ a $85 \%$ do peso bruto do coco verde é considerado lixo.

A fibra do coco maduro já vem sendo utilizada na agricultura e na indústria. Por sua vez, a fibra da casca do coco verde, que ainda não vem sendo amplamente utilizada, poderá se tornar matéria prima importante na produção de substratos de boa qualidade para a produção de mudas ou em cultivos sem o uso do solo. Neste caso, o aproveitamento da casca de coco verde é viável por serem suas fibras quase inertes e terem alta porosidade. A facilidade de produção, baixo custo e alta disponibilidade são outras vantagens adicionais apresentadas por este tipo de substrato. Para a obtenção da fibra e seu uso como substrato, a casca de coco passa por diversas operações como corte, desfibramento, secagem, trituração, lavagem e, quando necessário, compostagem.

\section{A matéria prima}

A casca do coco verde, matéria prima para a obtenção da fibra é na realidade, o fruto verde sem a água. A produção de coco, somente no interior de São Paulo, cresceu $68 \%$ em relação ao ano de 1999 , tendo sido colhidas 8,1 bilhões de unidades (Ripardo, 2000). Segundo folheto do Projeto Coco Verde (www.projetococoverde.com.br) haverá um acréscimo de $400 \%$ na produção de coco no Brasil nos próximos 3 anos. A área de produção, somente do coqueiro do tipo anão, dobrou no Brasil nos últimos cinco anos, passando de 25 para 50 mil ha. A grande expansão da produção de coco é a garantia da disponibilidade de matéria prima para a produção do substrato.

A coleta da casca é feita nos próprios locais de venda de água de coco, descartando-se aquelas de coloração marrom, porque apresentam maior dificuldade para serem processadas. O armazenamento da casca deve ser feito, preferencialmente, em local arejado, coberto e revestido de cimento. 
Fig. 1. Fluxograma para o aproveitamento da casca do coco verde para produção de substrato

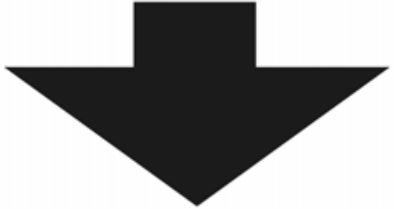

Coleta da matéria prima

* Escolher cascas de mesma procedência

* Selecionar cocos verdes
Desintegração/trituração da casca

* Cortar com o facão em pedaços

* Desfibrar com picadeira de forragem

* Triturar com peneira de $3 \mathrm{~mm}$ ou $4 \mathrm{~mm}$

\section{Lavagem das fibras}

* Usar água corrente de boa qualidade

* Amenizar a perda das partículas menores no processo de lavagem

\section{Armazenamento \\ * \\ Local limpo e higienizado}

\section{Compostagem das fibras para a produção de} mudas.

* Compostar no mínimo por 90 dias

* Enriquecer com nutrientes
Colocação em contentor para o cultivo sem solo

* Produção de hortaliças

* Fores em vasos

Figura 1. Fluxograma para o aproveitamento da casca do coco verde para produção de substrato

\section{Preparo da fibra.}

Para o preparo da fibra pode ser utilizada a máquina desintegradora/ trituradora de forragem, equipamento disponível na maioria das propriedades e de fácil aquisição. A casca deve ser cortada em pedaços para diminuir o embuchamento do sistema de alimentação da trituradora. Após o desfibramento, as fibras longas devem passar pela secagem ao sol por cerca de 4 dias ou até atingirem $15-20 \%$ de umidade. $O$ teor de umidade da fibra influencia no desempenho da máquina e no tamanho das partículas finais (Rosa et al., 2001). A trituração causa grande formação de poeira, portanto é recomendável que o operador use equipamento de proteção individual como máscaras, óculos e luvas. Para aumentar a capacidade de retenção de umidade e nutrientes deve-se diminuir o tamanho das fibras. Entretanto, quanto menor o tamanho da fibra mais difícil e demorado se torna o processo de trituração. A Embrapa Hortaliças tem usado, na trituradora, peneiras com furos de $3 \mathrm{~mm}$ ou $4 \mathrm{~mm}$ de diâmetro, com bons resultados para o cultivo sem solo, mas para a produção de mudas é recomendável substrato com granulometria ainda menor.

A casca de coco verde pode apresentar níveis tóxicos de tanino, de cloreto de potássio e de sódio, cujos teores podem ser reduzidos com lavagem em água corrente de boa qualidade, livre de substâncias químicas e patógenos. Para diminuir a perda de fibras de granulometria pequena, realizar a lavagem das fibras longas, antes da trituração.

Um processo de compostagem do substrato da fibra de coco por cerca de 90 dias é necessário quando o objetivo é a produção de mudas. O substrato feito a partir das fibras de coco não possue os nutrientes essenciais para as plantas. Portanto é preciso fornecê-los de acordo com as necessidades da espécie a ser cultivada adicionando-se adubos em pré-plantio ou, principalmente, em fertirrigação. As principais operações para a preparação de substrato a partir da casca de coco verde estão sintetizadas em um fluxograma apresentado na Figura 1.

As propriedades físico-químicas da fibra de coco variam bastante em fun- 
Tabela 1. Produção comercial do tomateiro cultivado em oito tipos de substratos. Brasília, Embrapa Hortaliças, 2002.

\begin{tabular}{|c|c|c|c|}
\hline \multicolumn{4}{|c|}{ Produção comercial de tomate $\left.{ }^{*} \mathrm{~kg} \mathrm{~m}^{-2}\right)$} \\
\hline Tipos de substrato & Ano $2000^{* *}$ & Ano 2001 & Ano 2002 \\
\hline Fibra de coco & $12,4 \mathrm{a}$ & $8,2 a b$ & $18,9 \mathrm{a}$ \\
\hline Pó de serra & $11,1 \quad b$ & 8,6 a & $17,2 a b$ \\
\hline Casca de arroz carbonizada & $11,6 a b$ & 7,0 bc & $15,2 a b$ \\
\hline Maravalha & $10,8 \quad b$ & $7,4 a b$ & $15,9 a b$ \\
\hline Comercial (Plantmax) & - & $7,6 a b$ & $14,7 \quad b$ \\
\hline Substrato do $\mathrm{CNPH}^{\star * *}$ & $10,5 \mathrm{bc}$ & $7,6 a b$ & $16,3 a b$ \\
\hline Casca de arroz cru & 9,9 & $6,0 \quad c$ & 11,1 \\
\hline Lã de rocha & 8,2 & $4,6 \quad d$ & 11,2 \\
\hline
\end{tabular}

* Números nas colunas seguidos da mesma letra não diferem entre si pelo teste de Tukey a $5 \%$ de probabilidade.

** Ano de 2000, adaptado de Carrijo et al. (2001).

*** Para o preparo do substrato do CNPH, mistura-se 3 carrinhos de terra de subsolo ou barranco, com 1 carrinho de casca de arroz parcialmente carbonizada e 1/3 carrinho de esterco de galinha. Para cada carrinho da mistura adicionar: 100g de 4-30-16, com 100g de calcário e $40 \mathrm{~g}$ de termofosfato com boro e zinco.

ção da fonte de matéria prima e do seu processamento. Sanches (1999) apresenta resultados de vários autores onde pode ser visualizada essa grande variabilidade. As propriedades físico-químicas da fibra apresentam os seguintes valores médios: $\mathrm{pH}=5,4$; condutividade elétrica $(\mathrm{CE})=1,8 \mathrm{dS} / \mathrm{m}$; capacidade de troca catiônica $(\mathrm{CTC})=92$; relação $\mathrm{C} /$ $\mathrm{N}=132 ; \mathrm{d}=70 \mathrm{~g} / \mathrm{L} ;$ porosidade total $=$ $95,6 \%$; retenção de água $=538 \mathrm{ml} / \mathrm{L}$; capacidade de aeração $=45,5 \%$ e água facilmente assimilável $=19,8 \%$. Um substrato ideal deve possuir, entre outras características, uma porosidade acima de $85 \%$, uma capacidade de aeração entre 10 e $30 \%$ e água facilmente assimilável de 20 a $30 \%$. Portanto, as propriedades da fibra de coco conferem ao seu substrato características de boa qualidade. A grande percentagem de lignina (35-45\%) e de celulose (23-43\%) e a pequena quantidade de hemicelulose (3-12\%), que é a fração prontamente atacada por microorganismos, conferem ao substrato de fibra de coco uma grande durabilidade (Noguera et al., 1998), sendo desta maneira, recomendável para cultivos de ciclo longo como as ornamentais. É também ideal para o cultivo de hortaliças sem o uso do solo, pois não sofre o processo de degradação acelerado causado pelo intensa aplicação de água e fertilizantes.
A comparação da fibra de coco com outros sete tipos de substratos mostrou uma leve superioridade da fibra de coco em termos absolutos na produção comercial de tomate, produzindo cerca de 1 tonelada a mais de frutos comerciais que o pó de serra ou serragem no três anos de avaliação (Tabela 1).

As boas propriedades físicas da fibra de coco, a sua não reação com os nutrientes da adubação, sua longa durabilidade sem alteração de suas características físicas, a possibilidade de esterilização, a abundância da matéria prima que é renovável e o baixo custo para o produtor faz da fibra de coco verde um substrato dificilmente superável por outro tipo de substrato, mineral ou orgânico no cultivo sem solo de hortaliças e flores.

Para o preparo de substrato com a fibra de coco, tanto para a produção de mudas ou no cultivo sem solo é importante que o agricultor conheça as recomendações técnicas do processo ou receba assistência técnica.

\section{LITERATURA CITADA}

BRASIL. Ministério do Meio Ambiente, dos Recursos Hídricos e da Amazônia Legal. Coco Verde. Disponível em: <http:// www.integracao.gov.br/pdf/frutiseries frutiseries_sp_03.pdf $>$. Acessado em 13/03/02.
CARRIJO, O.A.; REIS, N.V.B.; MAKISHIMA, N.; MOITA, A.W. Avaliação de substratos e de casa de vegetação para o cultivo de tomateiro na região de Brasília. Horticultura Brasileira, Brasília, v. 19, suplemento CD-ROM, 2001. Trabalho apresentado no $41^{\circ}$ Congresso Brasileiro de Olericultura, 2001, Brasília, DF.

NOGUERA, P; ABAD, M; NOGUERA, V; PURCHADES, R; MAQUIERA, A. Coconut coir waste, a new and viable ecologically-friendly peat substitute. Acta Horticulturae, 517 p. 279-286. 2000.

RIPARDO, S. Coco muda a paisagem do interior. Folha de São Paulo, São Paulo, 18 Jan. 2000. Agrofolha. Disponível em: < http:// www.uol.com.br/fsp/agrofolha.htm>. Acessado em 13/03/02.

ROSA, M.F; SANTOS, F.J.S.; MONTENEGRO, A.A.T.; ABREU,F.A.P.; CORREIA, D; ARAUJO, F.B.S.; NORÔES, E.R.V. Caracterização do pó da casca de coco verde usado como substrato agrícola. Fortaleza: Embrapa Agroindústria Tropical, 2001. 6 p. (Comunicado Técnico, 54).

SÁNCHES, F.P. Propriedades y características de los substratos. Turba y fibra de coco. In: FERNÁNDEZ, M.F. \& GÓMEZ, I.M.C. (ed). Cultivo sem suelo II. Curso superior de especializacón. p. 65-92. Almería, Espanha: Dirección Gen. de Investigación y Formación Agraria de la Junta de Andalucía/FIAPA/Caja Rural de Almería. 1999. 590 p. 